\title{
Economic Effects Model of Urban Population Structure in China
}

\author{
Wei WANG ${ }^{1, a}$, Jian-Kang YANG ${ }^{1, b,{ }^{*}}$ \\ ${ }^{1}$ School of Finance and Public Management, Harbin University of Commerce, Harbin, China \\ a63993022@qq.com, b243482675@qq.com \\ ${ }^{\star}$ Corresponding author
}

Keywords: Urban population structure, Age structure, Cultural quality structure, Regional structure.

\begin{abstract}
Based on the production function of Cobb Douglas and the model of Solow Growth, the paper built economic effects model of age structure, cultural structure and regional structure for urban population, which could be verified on the rationality by correlation coefficient and reliability, single integral test and co integration test, and by using national economy statistical data from 1995 to 2014.
\end{abstract}

\section{Introduction}

Since the reform and opening up of China, economic and social achievements have been made significantly, while national economy was in the sustainable development, the enormous changes of population structure were also undergoing in China. The population is both producer and consumer influenced national economy has attracted the attention of more governments. Household, family, education, urbanization and other relevant national policies gradually formed the population structure of age, culture and region, which has attracted extensive research on affecting national economy by home and abroad scholars.

Andersson (2001) have studied the proportion of working population of age structure and economic growth on Sweden, Denmark, Norway and Finland and other Nordic countries from 1952 to 1992, and concluded the above two were significantly positively relation [1]. Groezen et al. (2005) analyzed population aging and concluded that the aging of the population will promote the development of economy to some extent [2]. An-Gang HU, Sheng-Long LIU, Zhen-Guo MA(2012) used the Solow model to analyze the population aging degree to promote human capital stock and capital, national economic affected the rate of population growth, the population aging and economic slowdown have detrimental effects on population growth in China [3]. Ping LIU (2013) analyzed economic effect based on China population aging and Fang WANG (2013) indirectly affect population age structure on household consumption is greater than the direct effect, empirically verified by structural equation, the elderly dependency ratio of economic growth has a positive effect [4, 5]. Xiao-Qing ZHANG (2009) and Wei-Guo WANG (2004) constructed spatial econometric model, concluded that all working age population would promote economic growth using the census data[6, 7]. Mei-Feng WANG and Rong CHEN(2015) used CGE model to analyze the economic effect of quantitative analysis only changed the age structure of the population, simulating the population age structure change will lead to that economic growth rate is slowed[8]. Therefore, the economic effects of population age structure has become the focus of the scholars, although the age structure of the population laid more impact on economy, the scholars have not stretch consensus, but overall, the age structure will influence the economy through various functions, which will play the negative effect on national the economy while the population growth rate is slowed.

Denison (1962) analyzed the cultural quality of population in United States education from economic analysis during the period of 1929 to 1973, of which the economic contribution was about 20 percentage, workers' cultural and technical education of the average American labor efficiency increased by 0.97 percentage [9]. Guang-Hui SONG (2003) paid more emphasis on the growth of population cultural quality education during the period of 1981 to 2000, although the average cultural quality of population has been significantly improved through all levels of government investment, but the effects of economic growth led by these measures was not too dramatic, even was the negative 
effect [10]. Qian-Chang CHENG (2009) applied the statistical data of population culture quality structure and economic development from 1994 to 2006, Xian-Hong QIN (2008) used the relevant data from 1997 to 2005, Shu-Juan CHEN (2013) established VAR model, which showed a strong correlation between economic development and cultural quality of population [11, 12, 13]. Xiao-Hong HU (2012) used the method of gray correlation degree to draw a conclusion that the influence of the stock of labor quality on economic growth is relatively small [14]. Therefore, the influence of the population cultural quality structure on the economy growth is uncertain.

In the paper, we built the economics effect model based on the production function of Cobb-Douglas and the model of Solow growth, verify the rationality of the model by correlation coefficient, single integral test and cointegration test.

\section{Model Building}

Considering the technical progress in Solow model, the improved model is Eq.1,

$$
Y=F(K, L \times E),
$$

in which $\mathrm{K}$ is capital, $\mathrm{L}$ is the working population, $\mathrm{E}$ is labor efficiency, and $\mathrm{E}$ is the specific form of labor efficiency, So Eq.2 is as following.

$$
Y=A \times K^{\alpha} \times(L \times E)^{\beta} .
$$

In order to eliminate the possible effect of Heteroscedasticity, the logarithm of (2) is taken into account, and Eq.2 is changed to Eq.3,

$$
\log (Y)=\log (A)+\alpha \times \log (K)+\beta \times \log (L \times E) .
$$

By literature review of the former studies can be seen, the population structure can be divided into general age structure, population structure and cultural quality structure.

As Eq.4 is

$$
L \times E=\mathrm{L} 1 \times \frac{\mathrm{L} 2}{L 1} \times \frac{L 3}{L 2} \times \mathrm{K},
$$

in which L1 is total population of society, L2 is urban population, and L3 is employment population of urban population. $\mathrm{K}$ is the labor efficiency, the efficiency of Mankiw argued that labor is based on the role of Education [15]. The proportion of college students in the proportion of the total population was taken as an important indicator of cultural quality education, so the paper used the proportion of college graduates in the proportion of the working population as the efficiency of the labor force, that is Eq.5,

$$
\mathrm{K}=\frac{\mathrm{L} 4}{\mathrm{~L} 3},
$$

in which L4 is the number of college graduates. So putting Eq.4 and Eq.5 into the Eq.3 can be seen from Eq.6,

$$
\log (Y)=\log (A)+\alpha \times \log (K)+\beta 1 \times \log (\mathrm{L} 1)+\beta 2 \times \log \left(\frac{\mathrm{L} 2}{\mathrm{~L} 1}\right)+\beta 3 \times \log \left(\frac{L 3}{L 2}\right)+\beta 4 \times \log \left(\frac{L 4}{L 3}\right) .
$$

Simplifying from Eq.6 to Eq.7,

$$
y=\alpha 0+\alpha 1 \times x 1+\alpha 2 \times x 2+\alpha 3 \times x 3+\alpha 4 \times x 4+\alpha 5 \times x 5+\varepsilon,
$$

in which $y=\log (Y), x 1=\log (K), x 2=\log (L 1), x 3=\log \left(\frac{L 2}{L 1}\right), x 4=\log \left(\frac{L 3}{L 2}\right), x 5=\log \left(\frac{L 4}{L 3}\right)$. 


\section{Population Structure Model Validation}

According to Eq.7, the per capita GDP and per capita investment can show the level of economic development, because of the huge gap between urban and rural economic level and the gap level are often changing the level of rural economic development is vulnerable to the impact of policies at all levels, the first industry is mainly agricultural production activities [16]. In order to observe the law of the market effectively, we use the value added of the second industry and the sum of the value added of the production of the third industry to divide the urban population to describe the $\mathrm{Y}$, and to reflect the development of the economy through y. By the urban social investment divided by the urban employment population to describe the investment $\mathrm{K}$, using X1 to describe the impact of investment on the economy, which is reflected by $\alpha 1$. L1 is the total population of the society, using $\mathrm{X} 2$ to describe the impact of the total population on the economy, which is reflected by $\alpha 2$. Because L1 is the total population of the society, L2 is the urban population, which can be used to describe the impact of population structure on the economy, $\mathrm{X} 3$, and its influence is reflected by $\alpha 3$. Because the L2, L3 of urban population, urban labor force, according to the national bureau of statistics of labor force analysis, the working population over the age of 15 working population under the age of 65, L3 and L2 of age reflect the population in the proportion of the total population, total proportion raise the ratio of 1 minus, so X4 can depict the age structure of the population impact on the economy, whose influence can be reflected by $\alpha 4$. Due to the urban labor force, L3, L4 is the number of graduates of ordinary colleges and universities, so as to describe the impact of the cultural quality of the population on the economy on $\mathrm{X} 5$, which is reflected by $\alpha 5 . \alpha 0$ reflects the impact of other factors on economy, $\varepsilon$ is the system error. The above data are derived from the official website of the National Bureau of Statistics website (http://data.stats.gov.cn/) .

\section{Correlation Coefficient and Reliability}

According to the correlation coefficient and reliability in Table 1, the correlation coefficient between variables and y was higher than 0.9, and the reliability of the correlation was more than $99 \%$. Therefore, the construction of the model is so better.

Table 1. Correlation Coefficient and Reliability

\begin{tabular}{|l|l|l|l|l|l|}
\hline & $\mathbf{y}$ and x1 & $\mathbf{y}$ and x2 & $\mathbf{y}$ and x3 & $\mathbf{y}$ and x4 & $\mathbf{y}$ and x5 \\
\hline correlation coefficient & 0.994759 & 0.936287 & 0.944503 & 0.946605 & 0.945224 \\
\hline t- statistic & 41.27688 & 11.30995 & 12.19835 & 12.45701 & 12.28542 \\
\hline p(Probability $|\mathbf{t}|=\mathbf{0})$ & 0.000 & 0.000 & 0.000 & 0.000 & 0.000 \\
\hline
\end{tabular}

\section{Single Integral Test}

In order to avoid spurious regression of the model, it is necessary to make cointegration test for the above data. After a single integration test of $\mathrm{Y}, \mathrm{x} 1, \mathrm{X} 2, \mathrm{X} 3, \mathrm{x} 4, \mathrm{X} 5$, it is greater than in the corresponding critical values of the absolute value, the size and the Prod values of the variables are corresponding to the T value, at the significance level of $5 \%, \mathrm{y}, \mathrm{x} 1, \mathrm{X} 2 \mathrm{X} 3, \mathrm{X} 4$ and $\mathrm{X} 5$ were two order, so as to meet the cointegration test conditions, the results of the final two order single integration test are shown in Table 2.

Table 2. ADF Test Results

\begin{tabular}{|l|l|l|l|l|l|}
\hline List & T value & $\begin{array}{l}\text { critical } \\
\text { value(1\%) }\end{array}$ & $\begin{array}{l}\text { critical } \\
\text { value(5\%) }\end{array}$ & $\begin{array}{l}\text { critical } \\
\text { value(10\%) }\end{array}$ & $\begin{array}{l}\text { Prob } \\
\text { value }\end{array}$ \\
\hline $\mathbf{y}$ & -5.229186 & -4.667883 & -3.733200 & -3.310349 & 0.0038 \\
$\mathbf{x 1}$ & -4.658823 & -4.800080 & -3.791172 & -3.342253 & 0.0126 \\
$\mathbf{x 2}$ & -5.287212 & -4.616209 & -3.710482 & -3.297799 & 0.0030 \\
$\mathbf{x 3}$ & -5.101795 & -4.667883 & -3.733200 & -3.310349 & 0.0048 \\
$\mathbf{x 4}$ & -4.419801 & -4.6162209 & -3.710482 & -3.297799 & 0.0143 \\
$\mathbf{x 5}$ & -4.360011 & -4.6162209 & -3.710482 & -3.297799 & 0.0159 \\
\hline
\end{tabular}




\section{Cointegration Test}

Cointegration test is generally used by Johansen cointegration test and regression residuals stationarity test, the selected variables are integrated in two order, while the Johansen cointegration test is not suitable to single process inspection for the two order [17]. Therefore, the results of regression residuals stationary test can be seen in Table 3 based on Eq.7, we conclude that the regression residuals is smooth in the significant level of $5 \%$, namely $\mathrm{y}$ and $\mathrm{x} 1, \mathrm{x} 2, \mathrm{x} 3, \mathrm{x} 4, \mathrm{x} 5$ are in cointegration.

Table 3. results of co integration test

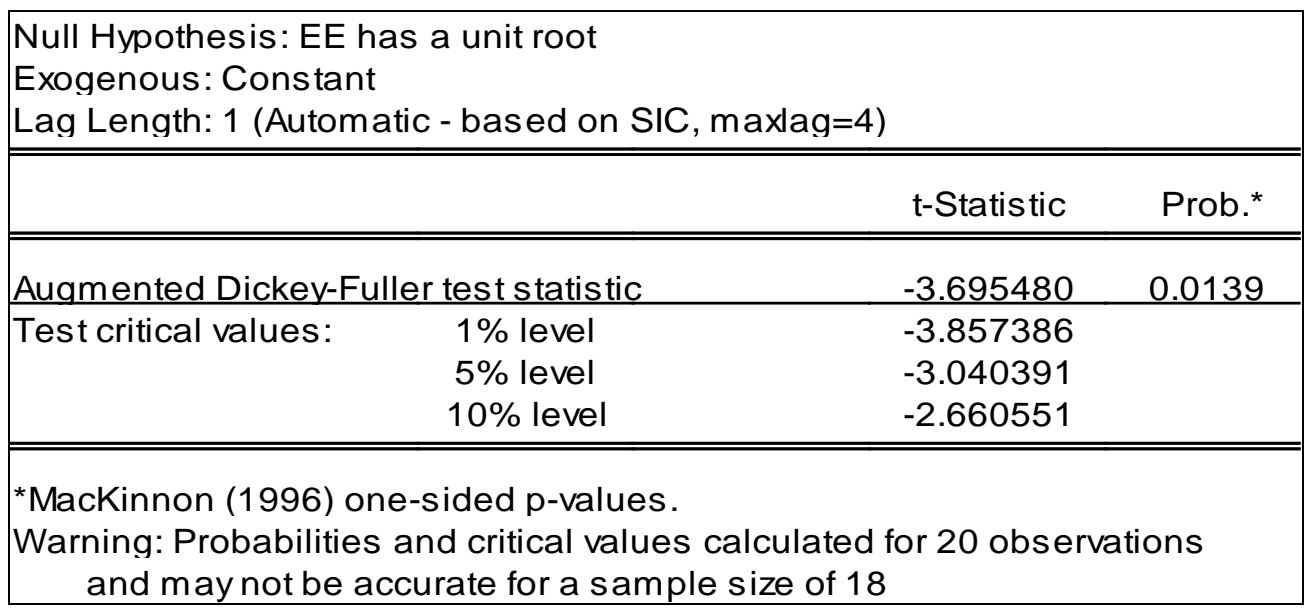

\section{Conclusion}

The paper studied on population structure under the development of economy and society, based on Douglas production function and Solow growth model, and built the economic effects model of age structure, culture quality structure and regional structure of urban population. Then the validation of the model is tested by correlation coefficient and reliability, single integration test and cointegration test from 1995 to 2014 in China, its results have shown that the effects of age structure can be adapted to national economy in China. However, the effects model focused on the relationship of contribution analysis on the variable level, but the weight evaluation and combination effect still need to be improved gradually in future researches, the conclusion analysis of the model is so simple, so as to collect and apply more and more data and the effective model to verify the rationality.

\section{Acknowledgement}

This research was financially supported by National Social Sciences Fund under grant 13AZD071, Humanities and Social Sciences Fund of Ministry of Education under grant 12YJC790190, Young Academic Backbone Support Program under grant 1253G029, Postdoctoral Scientific Research Initiation under grant LBH-Q14094, LKY-2016jx-09 of CALSS in China.

\section{References}

[1] Andersson B., Scandinavian evidence on growth and age structure, Regional Studies, 2001, (35), pp. 377-390.

[2] Van Groezen B, Meijdam L, Verbon H A A., Serving the old ageing and economic growth, Oxford Economic Papers, 2005, 57(4), pp. 647-633.

[3] An-Gang HU, Sheng-Long LIU, Zhen-Guo MA, Population aging, population growth and economic growth, Evidence from provincial panel data Chinese empirical evidence, Population Studies, 2012, 03, pp. 4-26. 
[4] Ping LIU, Study on the impact of population aging on China economic growth, Shandong University, 2013.

[5] Fang Wang, Analysis of the impact of population age structure on household consumption, Population and Economy, 2013, 03, pp. 12-19.

[6] Xiao-Qing Zhang, Study on the effect of population age structure on regional economic growth, China Population, Resources and Environment, 2009, 05, pp. 100-03.

[7] Wei-Guo WANG, Yong XU, Qiu-Ying LI, Quantitative analysis of the impact of population age structure on economic development in China, Market and Population Analysis, 2004, 06, pp. 1-8.

[8] Mei-Feng WANG, Rong CHEN, Study on the effect of population age structure change on China's economic development, Northwest Population, 2015, 03, pp. 95-99+105.

[9] Maddison A., Dynamic forces of capitalist development, Oxford University Press, 1991.

[10] Guang-Hui SONG, The contribution of the population with different educational level to China economic growth, An Empirical Analysis of the relationship between economic growth and education in China (1981-2000), Finance and Economics Science, 2003, 01, pp. 75-81.

[11] Qian-Chang CHENG, The interactive relationship between population cultural quality and the level of economic development, Resource Environment and Development, 2009, 01, pp. $15-18+21$.

[12] Xian-Hong QIN, Xiao-Gan YU, DUAN Xue-Jun, The spatial pattern and evolution of the population cultural quality in China, Journal of Graduate University of Chinese Academy of Sciences, 2008, 04, pp. 471-478.

[13] Shu-Juan CHEN, Zhi-Min SHOU, The research on the relationship between VAR model and cultural quality of population and economic growth in Shanghai and Gansu Province as an example, Financial Economy, 2013, 08, pp. 33-35.

[14] Xiao-Hong HU, Analysis of the effect of labor force cultural quality on economic growth, Journal of Chongqing Academy of Arts and Sciences, 2012, 03, pp. 57-59.

[15] Zhang Fan, et al., Macroeconomics, Beijing: China Renmin University press, 2009, pp. 178-225.

[16] Dan-Dan PENG, Research on the fiscal policy of the transformation of urban and rural economic structure of two yuan in China, Southwestern University of Finance and Economics, 2014.

[17] WANG Tao, et al., Econometric, Beijing: Science Press, 2015, pp. 45-48. 